\title{
A VERTICALIDADE DA CRÍTICA FOUCAULTIANA NA GENEALOGIA DA GOVERNAMENTALIDADE POLÍTICA
}

\author{
[THE VERTICALITY OF FOUCAULTIAN CRITIQUE IN POLITICAL GOVERNAMENTALITY \\ GENEALOGY]
}

\author{
Helrison Silva Costa* \\ Universidade Federal de Minas Gerais, Brasil
}

Resumo: O artigo tem por objetivo evidenciar a relação vertical entre crítica e governamentalidade desde quando estas noções são apresentadas por Foucault em 1978 por ocasião da conferência à Sociedade Francesa de Filosofia e durante o curso Sécurité, Territoire, Population no Collège de France. Nossa aposta consiste em afirmar que a governamentalidade é um tópico privilegiado no estudo das relações de poder, possibilitando uma análise crítica das formas de governo racionalizadas, cujos efeitos são a desmontagem dos esquemas de ordenamento históricos e o aparecimento das condições de possibilidade das "singularidades históricas" identificadas nas artes de governar. Assim, defendemos que a genealogia da governamentalidade é levada a cabo como crítica das práticas de governo entendidas como condução de condutas.

PalavRas-Chave: Foucault;Crítica; Governamentalidade; Genealogia; Governo
Abstract: The article aims to highlight the vertical relationship between criticism and governmentality since succh notions are presented by Foucault in 1978 on two different occasions: in the Conference to the French Society of Philosophy and during the course Sécurité, Territoire, Population, in the Collège de France. Our bet consists to claim that Foucault finds in the governamentality a special place to study the relations of power, which allow him to engage a critical analysis of rationalized forms of government whose effect are the disassembly of the historical schemas planning and the emergence of the conditions of possibility of "historical singularities" identified in the arts of governing. Thus, we argue that the genealogy of the governmentality is carried out as critical of the practices of government, understood as conduct of conduct. KEYWORDS: Foucault; Criticism; Governmentality; Genealogy; Government

\section{INTRODUÇÃO}

No início do curso de 1978 Securité, Territoire, Population Foucault retoma
o conceito de biopolítica apresentado no último capítulo de La Volonté de Savoir e trabalhado no curso de 1976 Il faut défendre la société a propósito do estudo das técnicas de governo que incidem sobre a vida da população, em seu aspecto biológico, cujo desenvolvimento extremado se deu com o nazismo e o stalinismo. Ora, o biopoder é precisamente a manifestação de uma racionalidade conjugada a uma forma de exercício de poder. Esta toma o ser humano enquanto espécie, inserindo-o em um conjunto populacional sobre o qual pode-se exercer formas de conduta e de governo tendo como referência os aspectos vitais e os traços biológicos, tais como, a reprodução da vida, crescimento, morte, o que permite traçar estratégias políticas como o controle

* Doutorando em Filosofia pela Universidade Federal de Minas Gerais, UFMG. Bolsista do Conselho Nacional de Pesquisa e Desenvolvimento,CNPq.m@ilto: hcosta.fil@outlook.com 
de natalidade, controle do crescimento vegetativo etc.

$\mathrm{O}$ anúncio de um estudo concernente à biopolítica paulatinamente é deslocado, a partir da problematização dos dispositivos de segurança surgidos na modernidade, para uma análise das práticas políticas que passam a referir a uma noção até então inédita no corpus foucaultiano, a saber, a governamentalidade. $\dot{E}$ a questão das práticas de 126 governo que parece modificar o percurso até então centrado no exame específico da biopolítica, inserindo essa problemática em um quadro que abrange as práticas de governo que investem sobre os indivíduos. Doravante, a biopolítica cede terreno para questões concernentes à governamentalidade. Tais práticas políticas começam a tomar forma no início da modernidade e trazem a característica de um governo ao mesmo tempo individualizante e totalizante, prerrogativa presente no poder pastoral que está na genealogia da governamentalidade.

Ainda no ano de 1978, em uma conferência proferida na Sociedade Francesa de Filosofia Foucault explicita a ideia de crítica em sua atividade filosófica inserindo-se na tradição Crítica inaugurada por Kant. Para isso, parte do Opúsculo "O que é o Esclarecimento?", texto no qual o autor opera a distinção entre Crítica e Aufklärung. Com efeito, a atitude crítica se aproxima daquilo que Kant designa como Aufklärung, o que permite a Foucault definir o seu próprio projeto crítico pautado na crítica incessante a um poder que se exerce.

Pensamos que o projeto filosófico foucaultiano assume como escopo a tarefa de realizar uma crítica das práticas refletidas de governo, a partir do jogo que se estabelece com as formas de resistência. Percebe-se no desenvolvimento do curso de 78 a vontade de realização de uma filosofia que desempenhe o papel de uma crítica da racionalidade moderna, especialmente em seu aspecto político. Dessa forma, nosso propósito é estabelecer as relações concernentes à crítica, tal como entendida em 1978, e os estudos sobre a governamentalidade presentes no curso desse mesmo ano, os quais permitem encetar uma análise crítica das formas de governo racionalizadas, cujos efeitos são a desmontagem dos esquemas de ordenamento históricos e o aparecimento das condições de possibilidade das "singularidades históricas" identificadas nas artes de governar. Assim, defendemos que a genealogia da governamentalidade é levada a cabo como crítica das práticas de governo entendidas como condução de condutas.

\section{I.A GENEALOGIA DA GOVERNAMENTALIDADE NO CURSO DE 78}

Em Sécurité, Territoire, Population o tema da governamentalidade mantém relação com a multiplicação das artes de governo no século XVI, a partir da crise duplamente estabelecida no fim do Medievo em relação ao funcionamento do poder de soberania e do poder pastoral. Ora, verifica-se a partir disso que o interesse se dá em torno dos problemas suscitados pela multiplicidade das práticas de governo. Nesses termos, a noção de governo se afasta da acepção contemporânea, entendida tão somente como administração ou como a instância do poder executivo de determinada unidade política e passa a ser entendida conforme a uma multiplicidade de atuações. Não se trata de examinar o governo a partir do ponto de vista do Estado, mas compreender os desdobramentos de suas múltiplas determinações efetivadas, por exemplo, no governo dos pais em relação aos filhos, do padre em relação à comunidade religiosa e mesmo do sujeito em relação a si mesmo. A abordagem do tema do governo é certamente mais complexa e fecunda, pois ao não reduzir a polissemia do termo, tal como encontrada no século XVI, Foucault é capaz de construir um caminho para empreender suas análises do poder que perpassa uma abrangência que compreende o governo dos outros e o governo de si mesmo.

A noção de governo é tomada no sentido múltiplo empregado no século XVI em oposição à significação estreita do termo na atualidade. Com efeito, esta compreensão é importante para modificar o entendimento que se tem da noção de poder. Nas pesquisas foucaultianas no fim da década de 70 , verifica-se o deslocamento de uma micropolítica 
das relações de poder normalizadas para uma análise das técnicas em que os sujeitos governam uns aos outros, de modo que o poder é entendido como relações estratégicas entre indivíduos para condução de condutas. Desse modo, busca-se apreender as relações de poder enquanto práticas de governo, a partir da constatação da ideia de que os indivíduos são governáveis. Logo, o que está em jogo nas relações de poder são as práticas de governo, ou seja, os modos de conduzir a conduta de outrem.

A trilha aberta pela questão do governo leva Foucault a se debruçar sobre a artes de governar que aparecem no século XVI oriundas da crise estabelecida na pastoral cristã e que desembocam na razão de Estado. Com isso nos encontramos no terreno da governamentalidade, onde tecnologias de poder se encontram com racionalidades específicas para se exercerem. Na razão de Estado vemos uma racionalidade propriamente política que se opõe ao discurso teológico-jurídico da soberania e, posteriormente, vemos as práticas de governo se alicerçarem em uma racionalidade científica de caráter econômico, formando a governamentalidade liberal, que apesar de todas as transformações que provoca mantém os mesmos propósitos da prática de governo pastoral concernente ao governo da conduta dos outros.

Além disso, sem abandonar a abordagem microfísica o curso de 1978 ao remodelar seu objeto de estudo para a dimensão mais ampliada de governamentalidade Foucault acaba por deparar-se com o problema do Estado, na medida em que esse aparece como lócus privilegiado de atuação do poder. Precisamente Foucault trata de descontruir a ideia de lugar privilegiado de análise, bem como coloca em xeque a existência cristalizada, forte e duradoura dessa instituição de modo que ele a percebe como um efeito do processo de governamentalização implementado a partir do século XVI; um efeito das relações estratégicas de poder abarcadas pela governamentalidade. $\mathrm{O}$ entendimento do poder como práticas de governo é desse modo radicalizado servindo, inclusive, para abordagem das práticas que compõem o Estado. Destarte, a governamentalidade permite tratar o problema da condução dos indivíduos fora das dimensões cristalizadas da correspondência entre governo e Estado, este último é tomado não como uma unidade oriunda da multiplicidade das relações de poder, mas ele mesmo é considerado como uma multiplicidade de forças.

$\mathrm{O}$ escopo da análise é identificar historicamente o momento em que o Estado "entrou efetivamente na prática refletida dos homens" e desse modo distinguir sobre quais condições o Estado se tornou objeto de conhecimento e de análise e passou a compor uma estratégia refletida, fazendo sua entrada "no campo da prática e do pensamento dos homens" (FOUCAULT, 2004b, p. 112). Seguindo o comentário de Candiotto (2010), podemos afirmar que aquilo que Foucault faz é perscrutar o aparecimento das formas de governo, que se desdobram em um Estado governamentalizado, no lugar de tentar compreender as transformações como uma crescente estatização da sociedade. E assim, Foucault pretende mostrar: "como se pode efetivamente realocar a emergência do Estado como aposta política fundamental no interior de uma história mais geral que é a história da governamentalidade ou ainda, se vocês quiserem, no campo das práticas de poder" (FOUCAULT, 2004b, p. 112).

Dito de outro modo, o Estado se constitui como efeito de práticas de governos e de um intenso processo de governamentalização ocorrido na sociedade. Isso implica em dizer que o Estado, precisamente o Estado administrativo, se forma pela atuação das práticas de governo que incidem sobre a população. Ele é produto de um arranjo de práticas e técnicas de governo que são constantemente mobilizadas e a todo tempo arranjadas de modo distinto para o governo dos outros. Esse modus operandis do poder tem como um de seus aspectos a sedimentação nas funções administrativas do Estado, motivo pelo qual podemos conceber essa realidade a que chamamos Estado, mas que é, como podemos perceber, bastante móvel e fluida haja vista o caráter instável da governamentalidade. Diante disso, Foucault constata:

Vivemos na era da governamentalidade, aquela que foi descoberta no século XVIII. Governamentalização do Estado que é um fenômeno particularmente 
retorcido, pois, se efetivamente os problemas da governamentalidade, as técnicas de governo se tornaram realmente a única aposta política e o único espaço real das lutas e disputas políticas, essa governamentalização do Estado foi do mesmo modo o fenômeno que permitiu ao Estado sobreviver. (2004b, p.112-113)

Podemos notar que o problema do governo é o eixo central que perpassa o tema da governamentalidade, inclusive para compreensão do Estado. Corrobora essa posição Gordon (1991), que vê na introdução do tema da governamentalidade uma maneira de Foucault mostrar a efetividade de seu método na abordagem de temas não circunscritos a uma dimensão micropolítica. A prática de governo se estende desde a antiguidade a partir do poder pastoral que procura conduzir as ações dos indivíduos em todas as dimensões e aspectos. A genealogia dessa prática de governo é importante para que o autor rastreie a história da governamentalidade moderna. Muitos dos aspectos do poder pastoral são reativados nas artes de governo racionalizadas que tomam forma a partir do século XVI na razão de Estado. Nela dá-se a forja de uma racionalidade especificamente política que se articula às práticas políticas abarcadas no mercantilismo, tais como o dispositivo de polícia e o dispositivo diplomático-militar. Por sua vez, a racionalidade política liberal no século XVIII traz intensas modificações das tecnologias de poder e se coloca como uma crítica constante aos modos de atuação da razão de Estado. Trata-se de uma crítica pautada em uma racionalidade econômica que efetua o aparecimento de uma governamentalidade outra.

$\mathrm{Na}$ perspectiva genealógica tanto a pastoral cristã, quanto a razão de Estado, bem como a governamentalidade liberal possuem um objetivo em comum: governar a conduta dos indivíduos, interferir sobre suas ações e sobre os modos de conduzirem a si próprios. Essas artes de governo incorrem em um nível ao mesmo tempo individualizante, pois interferem sobre as questões mais particulares dos sujeitos, e totalizante, pois interferem sobre todos os aspectos da vida dos indivíduos. Com isso, Foucault quer designar também o fato de que as práticas de condução de conduta são capazes de governar o sujeito enquanto indivíduos e enquanto pertencentes a um conjunto maior, seja uma comunidade ou, como se dará na modernidade, uma população. Desse modo, uma sociedade governamentalizada obedece a uma função de governo que se desloca do poder pastoral, cujo objetivo era assegurar a salvação da alma dos indivíduos (salut), até o objetivo de assegurar a salvação do indivíduo em seus aspectos vitais (santé) fora da transcendência, de modo que a prosperidade dos sujeitos governados possa ser garantida. Dito isso, é possível sustentar que a noção de governo no curso de 78 ocupa lugar central, permitindo a Foucault explorar as relações de poder sob os auspícios da governamentalidade que permite pensar o poder como condução de conduta.

\section{II.A CRÍTICA GENEALÓGICA DA GOVERNAMENTALIDADE MODERNA}

Segundo Foucault a crítica se coloca como uma questão indefinidamente aberta no interior da filosofia; a crítica possibilita o movimento da filosofia na medida inaugura condições para filosofias outras. Assim, ele aponta a radicalidade da crítica que atua como propulsora da filosofia e ainda adquire a proeminência para se firmar no lugar de "toda filosofia possível", de toda filosofia que não se proponha crítica. A crítica se faz presente não apenas nos limites da filosofia, na grande empreitada kantiana de formulação de uma filosofia crítica. Ela se configura por uma abrangência da crítica que ultrapassa os limites do âmbito teórico ao qual se liga a filosofia; a crítica se estende até o campo das práticas sociais em que se situam as ações humanas.

No início da modernidade desenvolveu-se um comportamento, uma maneira de agir e relacionar-se com o mundo que é específica a esse período. A esse ethos filosófico Foucault designa como atitude crítica. Assim, a identificação foucaultiana da crítica se faz presente nas práticas sociais como uma atitude, um modo específico 
presente no comportamento das pessoas que estabelecem relações umas com as outras e com as coisas exteriores a elas pelas quais são constantemente atravessadas. Essa definição de crítica não se conforma à filosofia, pois ultrapassa as dimensões teóricoabstratas desse conjunto de saber. Nesse sentido, concordamos com a opinião de Adverse que afirma: "a crítica como atitude, como Aufklärung, não pode, então, ser contida nos limites de um projeto filosófico, uma vez que se refere igualmente às formas de exercício de poder e às práticas sociais" $(2010, \mathrm{p} .4)$. Sendo assim, ainda que a crítica possa ser encontrada na filosofia não coincide com ela, no sentido de que não é reduzida a esse âmbito. A definição proposta indica uma pulverização da crítica entendida como atitude crítica, caráter disperso o qual não se deve querer reduzir. Desse modo, ao não incorrer em uma postura de tentar dar à crítica um caráter unitário é que Foucault percebe sua abrangência em práticas diversas que o permite aproximar essa atitude crítica de um ethos próprio da modernidade.

Ao definir a crítica a partir de uma atitude que se estabelece em relação aos atravessamentos que envolvem os sujeitos no mundo Foucault se afasta da concepção usual de crítica e concebe uma função distinta daquela até então atribuída a ela. A crítica não intenta verificar a legitimidade de um conhecimento. Isso seria conceder à crítica um papel de julgamento em que atuaria de modo a afastar um conhecimento de outros saberes válidos. Para Foucault, não há como supor um conhecimento verdadeiro que sirva de parâmetro para exame do conhecimento ele mesmo. Com isso, a crítica deixa de se ancorar nesse "imperativo geral" identificado com averiguação e afastamento dos erros na racionalidade. Assim, Foucault se distancia do sentido tradicional de crítica, entendida como um modo de proceder que visa a legitimar determinado conteúdo de saber ou deslegitimá-lo.

$\mathrm{Na}$ conferência de 78 Foucault procura fazer a história da atitude crítica e, para isso propõe um recuo histórico e argumentativo que o faz retomar as considerações empreendidas em torno do pastorado cristão no curso desse mesmo ano no Collège de France. Acreditamos que esse movimento aproxima Foucault do intento de situar o estudo da crítica no âmbito das análises do poder pastoral e da governamentalidade. A pastoral cristã tem seu surgimento a partir da ideia desenvolvida pela Igreja de que cada indivíduo deveria "ser governado e deixar-se governar" por toda a vida e em todas os detalhes no intuito de alcançar sua salvação; governado, também, "por alguém que o ligue a uma relação global e ao mesmo tempo meticulosa, detalhada, de obediência" (FOUCAULT, 2015, p.35). Essa arte de governar esteve por muito tempo ligada ao modo de vida monástico durante toda a Idade Média. No entanto, irá ultrapassar a dimensão até então restrita ao âmbito religioso, o que colocará em evidência a questão de como governar. Verifica-se a utilização de uma técnica que atrela os sujeitos a identidades fixas por meio de uma relação de obediência e por meio da produção de um discurso de verdade do sujeito sobre si mesmo. Conforme Gros (2006, p.161): "esse 'governo' pode tomar outras formas, mas sempre se reencontrará a articulação dos três termos: sujeito/poder/verdade”. Assim, essa tecnologia de poder foi responsável por produzir uma série de resistências a que Foucault denomina de contracondutas. A esse movimento de reação às investidas de poder em seu funcionamento pastoral e na governamentalidade política Foucault vai designar como atitude crítica que se formula como um comportamento da sociedade moderna de recusa frente ao exercício das práticas de governo.

Com efeito, o aparecimento da atitude crítica como um ethos predominante na modernidade liga-se à problemática crescente e cada vez mais central das artes de governo na modernidade que remonta ao surgimento do poder pastoral. Esses dois acontecimentos estão relacionados na medida em que as investidas de poder geram reações por parte de quem está sendo governado. Sendo assim, a especificidade da atitude crítica a qual nos referíamos pode ser extraída da relação com o avanço da governamentalização da sociedade intensificada a partir da modernidade, de modo que: "a crítica, tal como se encontra aqui identificada, não é uma teoria, nem uma doutrina, nem um sistema: é uma recusa em ser governado assim ou desse modo, uma recusa em 
obedecer" (GROS, F. 2006, p.162). A crítica foucaultiana se define em relação à atitude crítica formulada a partir da análise das contracondutas religiosas desenvolvidas no seio das lutas antipastorais e, portanto, se caracteriza pela dispersão e não-identificação com um sistema filosófico.

Compreendemos que a história da atitude crítica se escreve concomitantemente à 130 história da governamentalidade, no contexto de emergência do poder pastoral. Sendo assim, conforme a observação de Senellart crítica e governamentalidade são "questões aparentemente distintas, mas que de fato são solidárias umas com as outras" (1995, p.3), haja vista que a atitude crítica se coloca como uma maneira de agir específica da modernidade, período em que se deu a ampliação das práticas de governo nas mais variadas relações humanas configurando um intenso processo de governamentalização. Dessa feita, a atitude crítica é o movimento de resistência e enfrentamento às investidas de práticas de condução de conduta cada vez mais intensas característico das sociedades governamentalizadas.

A relação existente entre a atitude crítica e as artes de governo se estabelece a partir do processo de governamentalização que caracteriza as sociedades modernas e que vem acompanhado da questão: “como não ser governado?". Com isso, não há a afirmação de um comportamento de recusa total em relação ao governo que se expressaria em "como não ser governado de modo algum", designa, contudo, que frente às investidas da governamentalização que incide sobre a sociedade e sobre os indivíduos observa-se uma repetida conduta que coloca a questão: "como não ser governado desse modo, por aquilo, em nome desses princípios, em vista de tais objetivos e por meio de tais procedimentos, não dessa forma, não por isso, não por eles"( FOUCUALT, M. 2015, -.37). Não uma recusa total, portanto, mas como uma maneira refletida de se colocar frente às práticas de governo e que traz a prerrogativa de inquerir o modo como se é governado e de recusar determinadas formas de sê-lo. Nessa forma de se deixar conduzir, sem recusar completamente as práticas de governo, e tampouco aceitá-las de maneira irrestrita, Foucault percebe justamente um modo de governar-se a si mesmo que caracteriza como atitude crítica. Corrobora essa posição Serge Audier para quem Foucault teria identificado uma "tendência oposta" à investida do poder, "a qual imediatamente e muito concretamente põe a questão dos limites do governo e deste modo seus excessos. É contra esse pano de fundo que se pode discernir a emergência de uma atitude crítica" (2015, p.408) .

Sendo assim, a atitude crítica se desenvolve conjuntamente ao processo de governamentalização ocorrido na Modernidade: "como parceira e adversária ao mesmo tempo das artes de governo, como maneira de desconfiar-se delas, de recusá-las, de limitá-las, de encontrar nelas uma justa medida, de transformá-las, de procurar escapar a estas artes de governar. Durante este período Foucault acredita ter surgido na Europa uma "forma cultural geral ao mesmo tempo moral e política" que corresponde à "arte de não ser governado desse modo" ao que ele propõe então uma precisão maior quanto à definição de crítica justamente isso: "a arte de não ser tão governado" (FOUCAULT, 2015, p.37). A compreensão da crítica refere-se, portanto, à sua acepção como atitude crítica que caracteriza o comportamento da sociedade moderna em seu processo de governamentalização como recusa em ser completamente governado.

Procurando elidir o caráter genérico dessas afirmações Foucault situa historicamente a atitude crítica em três pontos de ancoragem. Primeiro, no retorno às Escrituras. $\mathrm{O}$ autor remete ao fato de que o governo dos homens consistia em uma prática de cunho espiritual perpetrada pelo poder da Igreja em face de sua autoridade que lhe garantia exclusividade de acesso ao texto sagrado, bem como a sua interpretação. Tal prerrogativa garantia à Igreja exercer um governo sobre a conduta dos homens, colocando-os em uma relação de saber-poder em que se fazia uso das Escrituras para instituir uma verdade como dogma e fazer funcionar o poder Eclesiástico. Desse modo, Foucault vê o movimento de retorno às Escrituras como uma maneira de recusar essa forma de governo.

Segundo, na crítica jurídica. A não aceitação das leis por estarem atreladas a um 
uso de coação pelo soberano, em maior ou menor grau conforme a época, mas que sempre esconde uma ilegitimidade. Nesse contexto, a crítica se efetiva não apenas pela desobediência às leis como também na defesa dos direitos universais e imprescritíveis aos quais todos os governos têm por obrigação se submeter. Assim, o modo de enfrentamento à autoridade despótica é realizado por meio de uma crítica no âmbito político efetivada por um viés jurídico que questiona as leis injustas impostas aos cidadãos.

Terceiro, não ser governado de determinado modo implica também em não tomar como verdadeiro o discurso de alguma autoridade apenas porque é proferido por ela. Dito de outro modo, um indivíduo apenas deve aceitar um discurso de autoridade se levar em consideração suas próprias razões para fazê-lo, desde que esteja convencido, por meio de boas razões, que o que lhe é proposto é verdadeiro. Uso da crítica, portanto, tal como inaugurado por Kant.

Vê-se assim o que Foucault quer designar por atitude crítica enquanto uma forma de não ser governado de determinado modo. Em qualquer âmbito em que atua, a atitude crítica é responsável por questionar a verdade estabelecida seja nas Escrituras, nas leis ou nos discursos científicos. Por meio desses três exemplos Foucault quer demonstrar a relação existente entre o jogo da governamentalização e da atitude crítica que atua em dimensões sociais distintas. A partir dessa verificação histórica Foucault constata que a crítica mobiliza um feixe de relações que liga o poder, a verdade e o sujeito um em relação aos outros, permitindo que a crítica possa ser tratada em meio a essa triangulação nos seguintes termos:

Se a governamentalização, é precisamente esse movimento pelo qual se trataria na realidade mesma de uma prática social de assujeitar os indivíduos por mecanismos de poder que reclamam de uma verdade, pois bem, eu diria que a crítica é o movimento pelo qual o sujeito se dá o direito de interrogar a verdade sobre seus efeitos de poder e o poder sobre seus discursos de verdade. (FOUCAULT, 2015, p.39).

A articulação que se estabelece entre a governamentalização e a atitude crítica é perpassado, portanto, pelo feixe de relações que liga o sujeito, a verdade e o poder. Nota-se que Foucault lida com esses termos de uma maneira que passa ao largo de uma simples relação de oposição, pois a atitude crítica não visa ao desaparecimento das formas de conduta e, por isso mesmo, configura uma relação mais complexa, a saber, de luta e enfrentamento. Desse modo, se estabelece a circulação de discursos de verdade que geram efeitos de poder, o que tem como efeito o assujeitamento dos indivíduos. No entanto, esse assujeitamento não é facilmente levado a cabo, pois a governamentalização ela mesma engendra reações por parte daqueles sobre os quais as práticas de poder investem e que por isso não querem ser totalmente governados. Os sujeitos em meio a esse feixe de relações assumem uma atitude crítica na medida em que questionam as práticas de governo, a verdade sobre a qual estão ancoradas e os efeitos de poder que ela faz funcionar. Assim, Foucault afirma que a atitude crítica se coloca como "arte da indocilidade refletida" e da "não-servidão voluntária" (FOUCAULT, 2015, p.39).

A partir disso, é possível afirmar uma concomitância entre um poder que se exerce e o modo como se resiste a ele. De onde podemos afirmar que o conjunto de definições acerca da atitude crítica se encontra na linha de um pensamento que procura pensar as formas de resistência frente às práticas de governo. Por conclusão, se estabelece a correspondência entre a governamentalidade e a atitude crítica, pois se a governamentalização tem como efeito o assujeitamento, a atitude crítica é a prática que funcionará como desassujeitamento nesse jogo denominado como "política da verdade" (FOUCAULT, 2015, p.39). Ademais, sublinhamos que Foucault utiliza-se dessas ancoragens históricas para marcar sua aproximação com o pensamento de Kant, mais precisamente com o modo em que o alemão defíne a Aufklärung e apoiar a crítica na noção de atitude crítica. 
O modo com o qual Foucault toma o problema da Aufklärung nos coloca no âmbito da governamentalidade moderna tal como apresentada no curso de 78. Assim, o autor vai desenvolver na conferência desse mesmo ano a afirmação de que essa definição de crítica é muito próxima daquilo que Kant designa como Aufklärung. Não vamos aqui analisar os detalhes da intricada relação entre Foucault e Kant. A nosso 132 propósito cabe apenas explicitar a inserção da atitude crítica desdobrada das contracondutas na perspectiva de uma filosofia crítica. $\mathrm{O}$ que interessa reter é a relação que a crítica mantém com o poder, mais precisamente com o excesso de poder, que se traduz no modo pelo qual se dá a genealogia foucaultiana das práticas políticas racionalizadas.

De fato, o problema do excesso de poder é o problema movente da filosofia na contemporaneidade de Foucault. Na conferência La philosophie analytique de la politique proferida no Japão em abril de 1978, o autor evidencia o problema do excesso de poder como um acontecimento na história do Ocidente e que é denunciado a partir do questionamento possibilitado pela crítica do conhecimento que questiona os avanços da racionalização. Nessa ocasião Foucault vai evidenciar a relação entre o excesso de poder e a crítica, de maneira que ele vai designar à filosofia o papel de lidar com os efeitos de poder. Para Foucault (2001), um dos papéis mais antigos do filósofo - do intelectual- foi o de colocar um limite à superprodução do poder todas as vezes em que ela estava em vias de se tornar uma ameaça, de modo que ele aparece em variados contextos, desde a Antiguidade, como um anti-déspota, atitude expressa na atuação como legislador (Sólon), como conselheiro político (Platão) e ainda no riso do cínico face ao poder. Em todos esses exemplos vê-se uma exterioridade do filósofo em relação ao poder. Para Foucault, esse quadro não cessa de retornar, mantendo sempre uma oposição entre o filósofo e o príncipe, entre a reflexão filosófica e o exercício do poder. Nesse sentido, a aposta do autor é a de que a filosofia ainda desempenha um papel de moderação em relação ao poder.

Ora, diante da constatação de que prevalece um excesso de poder nas práticas políticas da modernidade denunciada pela crítica à racionalização em sua relação com o poder, Foucault declara ser possível algumas atitudes. Uma delas consiste em interrogar historicamente os laços entre filosofia e poder, se perguntando como essa relação pode se estabelecer justamente quando a filosofia se apresentava como "moderação de poder", responsável, portanto, por impedir os excessos de poder. Essa postura levanta a suspeita de que a filosofia, ao impedir os avanços do poder, esconde a pretensão de que ela mesma anseia assumir o lugar do poder. Outra atitude possível seria no lugar de se perguntar pela relação entre filosofia e poder, opor esses termos, afirmando uma exterioridade da filosofia em relação ao poder. Nesta perspectiva, designa-se como filosofia apenas as reflexões concernentes à questão da verdade e do ser. Impede-se a filosofia de tentar embrenhar-se em domínios empíricos, tais como o do poder, pois isto significaria se comprometer. Entre essas duas atitudes, Foucault vislumbra ainda uma outra. Esta consistiria em tomar o poder em sua relação com a filosofia, não como fundação ou recondução do poder, mas do lado do "contra-poder", mas que não atuaria de maneira autoritária, profética, pedagógica ou normativa. Colocando-se como contrapoder o papel da filosofia é o de analisar, elucidar, tornar visível e intensificar as lutas em torno do poder, "as estratégias dos adversários no interior das relações de poder, as táticas utilizadas, os focos de resistência, somente se, em suma, a filosofia para de colocar a questão do poder em termo de bem ou de mal, mas em termo de existência" (FOUCAULT, 2001, p.540). Trata-se de apreender o poder no exterior de um quadro moral e jurídico e no lugar de perguntar pela legitimidade ou ilegitimidade do poder perguntar em que consistem as relações de poder.

Foucault se aproxima, portanto, dessa terceira atitude, pois, entende que "o papel da filosofia não é o de descobrir o que está escondido, mas de tornar visível o que precisamente é visível", ou seja, o que está de maneira tão próxima a nós e que por isso mesmo não podemos perceber. Com efeito, afirma o autor: "o papel da ciência é o de fazer conhecer aquilo que nós não vemos, o papel da filosofia é o de fazer ver aquilo 
que nós vemos" (FOUCAULT, 2001, p.541). Vemos, portanto, que a atitude possível no que tange à questão da Aufklärung de examinar os excessos de poder passa também por um problema de método: diante da constatação dos excessos de poder Foucault assume uma postura de verificar aquilo que o produz. Empreende-se, assim, uma prova de acontecimentalização no intuito de levar a cabo uma prática histórico-filosófica que realiza a crítica das práticas de governo. A prática histórico-filosófica não se interessa por "saber o que é verdadeiro ou falso, fundado ou não fundado, real ou ilusório, científico ou ideológico, legítimo ou abusivo" (FOUCAULT, 2015, p.51). Não se trata de uma análise de conteúdo que seria verificada conforme a uma verdade exterior, o que interessa é, primeiramente: "tomar os conjuntos de elementos onde pode-se identificar numa primeira abordagem, portanto, de modo totalmente empírico e provisório, as conexões entre os mecanismos de coerção e os conteúdos de conhecimento" (FOUCAULT, 2015, p.51). Desse modo, a crítica que Foucault pretende erigir ou que efetivamente lança mão em suas análises, aborda o conhecimento com vistas a localizar, no jogo de forças das práticas de saber-poder quais são os efeitos de verdade que ele produz e que por sua vez reforçam as relações de poder. Em nossa argumentação, é esta a atitude levada a cabo por Foucault em sua genealogia da governamentalidade, de modo que o autor se utiliza da crítica enquanto procedimento filosófico para recompor as descontinuidades das práticas de governo racionalizadas. Em suma, a genealogia assume contornos de crítica, ou ainda, a crítica se realiza pela genealogia.

Considerações finais

O projeto crítico foucaultiano assinala definitivamente o uso da genealogia na investigação das práticas não-discursivas, manifestas nas formas de poder, enquanto singularidades históricas. Temos assim que em 1978 Foucault apresenta o problema da governamentalidade no Ocidente e pouco tempo depois, nesse mesmo ano, ele explicita o escopo crítico de seu pensamento e confere à filosofia o papel de vigiar os abusos do poder. Portanto, é a questão do poder, imbricada na concepção de governo, que marca a entrada de Foucault no âmbito da crítica, uma crítica da razão política que se efetiva genealogicamente com vistas a identificar as singularidades históricas.

Destacamos também que em nossa análise verificamos que a governamentalidade se define como a apropriação de uma racionalidade pelas práticas de governo para definir as estratégias de condução dos homens e legitimar os efeitos de saber e poder. Vimos que a crítica acompanha esse movimento, no sentido de possibilitar a resistência à efetivação das tecnologias de poder. Estabelece-se, assim, a relação entre crítica e governamentalidade, relação esta necessária, posto que toda forma de poder se insere em jogos de força aonde são produzidas reações à atuação do poder ele mesmo. No curso de 78 essa relação é expressa enquanto conduta/contraconduta, haja vista que toda forma de prática de governo que atua sobre a conduta dos indivíduos deixa aberta a possibilidade de reação na forma de contraconduta. No jogo das relações de poder que constituem a governamentalidade as resistências ao poder aparecem como "catalisadores químicos" das relações de poder, o que confere a elas um contorno múltiplo, específico ao próprio campo aonde o poder se exerce. Configura-se no campo das relações estratégicas aquilo que Foucault chama de luta. As lutas são empreendidas de forma localizada em relação às práticas de governo que visam transformar os indivíduos em sujeitos por meio de técnicas específicas de poder, de modo que aquilo que constitui o horizonte das lutas na modernidade, como bem pudemos observar, é a recusa de determinado modo de subjetivação e o controle impostos pelas práticas refletidas de governo que atam os indivíduos a identidades préfixadas. A identidade se torna um problema contemporâneo de expressiva importância na luta política.

Assim, há uma relação inextrincável entre filosofia e o poder que consiste precisamente no fato de que a primeira deve se formular como crítica, podendo ser instrumento no enfrentamento às práticas de governo. A filosofia, então, se define como política da verdade, pois é nesse terreno das relações estratégicas que comportam o 
sujeito, a verdade e o poder que a crítica deve atuar. É preciso pensar de maneira outra, alterando as relações de poder em que nos encontramos. Para isso é necessária a crítica entendida como atitude crítica aonde estão ancoradas as resistências. É preciso se recusar, incessantemente, a ser totalmente governado. A filosofia, nesses termos, apenas adquire existência enquanto crítica. Ela é o discurso de enfrentamento no plano das relações estratégicas e enquanto crítica a filosofia deve poder identificar o conjunto de entrecruzamentos que pautam as relações de poder.

\section{REFERÊNCIAS}

ADVERSE, Helton. Para uma crítica da Razão Política: Foucault e a Governamentalidade. In: Revista Estudos Filosóficos. São João Del Rei, n 4, p. 1-25, 2010.

AUDIER, Serge. Neoliberalism through foucault's eyes. In: History and Theory. n. 54, p. 404$418,2015$.

CANDIOTTO, César. Foucault e a crítica da verdade. Belo Horizonte: Autêntica Editora, 2010.

FOUCAULT, Michel. Dits et écrits II- 1976-1988. Paris : Gallimard, 2001.

FOUCAULT, Michel. Le naissance de la biopolique. Paris : Gallimard/ Seuil, 2004a.

FOUCAULT, Michel. Sécurité, territoire, population. Paris : Gallimard/ Seuil, 2004b.

FOUCAULT, Michel. Qu'est-ce que la critique? Suivi de la culture de soi. Paris : Vrin, 2015.

GORDON, Colin. Governmental rationality: an introduction. In: The Foucault Effect: studies in governmentality. Chicago, p.1-52, 1991.

GROS, Frédéric. "Foucault et la leçon Kantienne des Lumières". In: Lumiéres. Bordeaux. Bordeaux, n. 8, p. 159-167, 2006.

LEMKE, Thomas. Foucault, governmentality, and critique. In: Rethinking Marxism Conference, University of Amherst, 2000.

LORENZINI, Daniele. From conter-conduct to critical atitude: Michel Foucault and the art of not being governed quite so much. In: Foucault studies, n.21, p. 7-21, 2016.

LORENZINI, D; DAVIDSON. I, A. Introduction. In: Qu'est-ce que la critique suivi de la culture de soi. Paris, Vrin, 2015.

SAVOIA, P. Foucault's critique of political reason: individualization and totalization. In: Revista de estudios sociales. Bogotá, n. 43, p. 14-22, 2012.

SENELLART, M. A crítica da razão governamental em Michel Foucault. Tempo Social; Rev. Social. São Paulo, v. 7, n. 1-2, p.1-14,1995.

SENELlART, M. Situation des cours. In: Securité, Territoire, Population. Paris: Gallimard/Seuil, 2004.

STIVAL, L, M. Política e moral em Foucault. Entre e a crítica e o nominalismo. São Paulo: Loyola, 2015. 